\title{
PROJECT DELIVERY THROUGH LEAN PRINCIPLES ACROSS ALL DISCIPLNES OF CONSTRUCTION IN A DEVELOPING COUNTRY ENVIRONMENT
}

\author{
Kaezad Karanjawala ${ }^{1}$, Diamond Baretto ${ }^{2}$
}

\begin{abstract}
Construction Industry has to counter many challenges and research studies have indicated that large projects across various asset classes typically take longer to finish than scheduled and tend to overshoot the budgeted cost. Improving labour productivity in all trades of construction has been found to be very challenging as compared to the manufacturing industry due to migrant labour, low skills and lower penetration of technology and mechanisation at the work sites. The high percentage of wastes generated in construction projects also puts tremendous pressure on natural and human resources.
\end{abstract}

In order to mitigate the above-mentioned challenges and risks and to improve our way of working, an organization embarked on the Lean journey starting with its Residential Towers using Partnering and other Lean principles for multiple stakeholder management across all our projects.

Also, to make the planning process predictable and create commitment based culture the organization amalgamated Lean into Critical Path Method by creating a Milestone Schedule given by the Top management. The Phase Schedule is derived from the Milestone Schedule and further broken down for weekly tracking into Look Ahead Plans (LAP). The LAP is prepared by field teams and is reviewed using Last Planner Meetings (LPS) and other lean tools and methodologies.

This paper portrays an organisation's Lean journey from residential to industrial projects using case studies with key learnings to explain how the success of Lean implementation is possible only when there is a cultural change brought among all the project stakeholders to strengthen team spirit and drive improvement initiatives with strong support from the Top Management. A focussed approach and imbibing the cultural changes in the organisation help to overcome all the barriers faced in the Lean Journey.

1 Associate Vice President - Godrej Construction, Godrej \& Boyce Mfg Co. Ltd, Vikhroli, Mumbai, India; +91- 9820509237; kaezad@godrej.com

2 Assistant General Manager - Godrej Construction, Godrej \& Boyce Mfg Co. Ltd, Vikhroli, Mumbai, India; +91- 9819345312; diamond@ godrej.com 


\section{KEYWORDS}

Lean construction, collaboration, value stream, Last Planner, customer delight

\section{INTRODUCTION}

Timely delivery of the project plays a very crucial part in the survival and business performance of any organization. The organizations' rationale for implementation of Lean Construction and its various tools and techniques was with the intent of improving the cost, quality, and time and safety metrics for a project while ensuring that customer commitments are met.

According to a study by Bhim Singh - Lean implementation and its benefits to production industry- year 2010) in the production sector it is possible to quantify benefits of Lean implementation by using tool of Value Stream mapping and the operator efficiency increased by approximately $40 \%$ along with reduction in other parameters like in lead time (83.14 percent), processing time (12.62 percent), work-in-process inventory (89.47 percent), and manpower requirement (30 percent).

B Singh, SK Sharma (Measuring Business Excellence, 2009) also explains how Value Stream Mapping (VSM) is helpful in lean implementation and to develop the road map to tackle improvement areas to bridge the gap between the existing state and the proposed state of a manufacturing firm.

The organization in its nascent phase of Lean implementation had to face many barriers and a comparison between our findings after implementation across 4 projects with the study for typical barrier identification by Jagdish R. Jadhav ,Shankar S. Mantha Santosh B. Rane (Exploring barriers in lean implementation- Dec 2014) and also reinforces and reiterates that the success of lean implementation will not be entirely based on application of appropriate tools and techniques alone but also on the top managements' involvement and leadership, workers' attitude, resources and the organizational culture. Saja Albliwi (in the year 2014) has also explored the critical failure factors for Lean Six Sigma in different sectors, and indicated certain common factors for failure, such as a lack of top management commitment and involvement, lack of communication, lack of training and education, limited resources and others.

The "lean" approach eliminating non-value activities from work processes by applying a robust set of performance change tools and emphasizing excellence in operations to deliver superior customer service-has become legendary in improving manufacturing companies' operations and profitability states Max Allway, Stephen Corbett (Shifting to lean service: Stealing a page from manufacturers' playbooks- Feb 2002)

Hence, it is evident from past research done on Lean construction that it aids successful completion of projects and Lean tools help identify and reduce wastes. This paper uses case studies with key learnings to elaborate an organisations Lean journey and the main contribution is to help new lean practitioners in developing countries such as India to execute projects successfully using Lean. 


\section{THE LEAN STORY IN A LEADING CONSTRUCTION ORGANIZATION}

\section{CASE STUDY 1 - CONSTRUCTION OF RESIDENTIAL PROJECT, MUMBAI (LEAN OBJECTIVE - BENEFITS OF PARTNERING IN LEAN PHILOSOPHY)}

The organization began by embarking on the Lean Journey way back in 2011 with Institute for Lean Construction Excellence (ILCE) for guidance to drive partnering using the Lean Philosophy of Collaboration with our vendors in the Project. It conducted a Workshop / Partners Meet with all its vendors and the Top Management which involved Team building games, Sharing of Project related experiences by vendors \& Painting competition with Lean Construction Theme.

The focus at this preliminary stage was on gaining trust by increasing transparency with stakeholders necessary for creating a firmer foundation for implementing Lean Construction. The project was at the finishing stage in which handover to customers was scheduled in the next three months. Involving contractors and sub-contractors and changing the methodology from independent team schedules to a schedule based on the work flow methodology for the project. By doing this, handover the flats on time by improving the flow of work on site using tools such as Weekly work plans, visual control of processes and team meetings. However, since Lean was applied at the finishing stage of the project, substantial benefits could not be achieved.

\section{CASE STUDY 2 - CONSTRUCTION OF INDUSTRIAL PLANT, AMBERNATH (LEAN OBJECTIVE - PARTNERING FOR INDUSTRIAL PROJECT)}

Based on the early learnings in concluding phase of the organizations residential project, it was decided to improve certain aspects of applying Lean Partnership Philosophy at its next project for the organisations Business Unit (2012). A workshop was conducted to evolve an appropriate Project Charter by involving all concerned stakeholders to get their commitment to deliver project on time and within the budget. The project was named "Project Delight". It captured the following key objectives of all stakeholders Safety first, Positive Attitude, Team Spirit - Have Fun, Effective communication, Proactive approach, Care for Environment and Society and Profit for all.

\section{KEY LEARNINGS FROM CASE STUDY 1 AND 2}

In these two projects, the organization was partly successful in implementing its Lean plan. While it did achieve marginal savings in time and cost, it could not completely align all our partners towards the common cause. Despite the good efforts put in by many of the stakeholders, some issues were not effectively resolved on time due to the trust deficit that is commonly observed in many construction projects. However, these early learnings were useful in implementing Lean more effectively in the organisations subsequent projects.

\section{CASE STUDY 3 - CONSTRUCTION OF HIGH RISE TOWERS, MUMBAI}




\section{(LEAN OBJECTIVE - IMPROVING PROJECT PERFORMANCE BY CONSTRAINT MANAGEMENT)}

Having gained a better understanding of certain Lean principles, the organization was now ready to deploy a few Lean tools on our next project - Construction of Tower B1 and B2 (FY 13-14) from the early construction stage of the project.
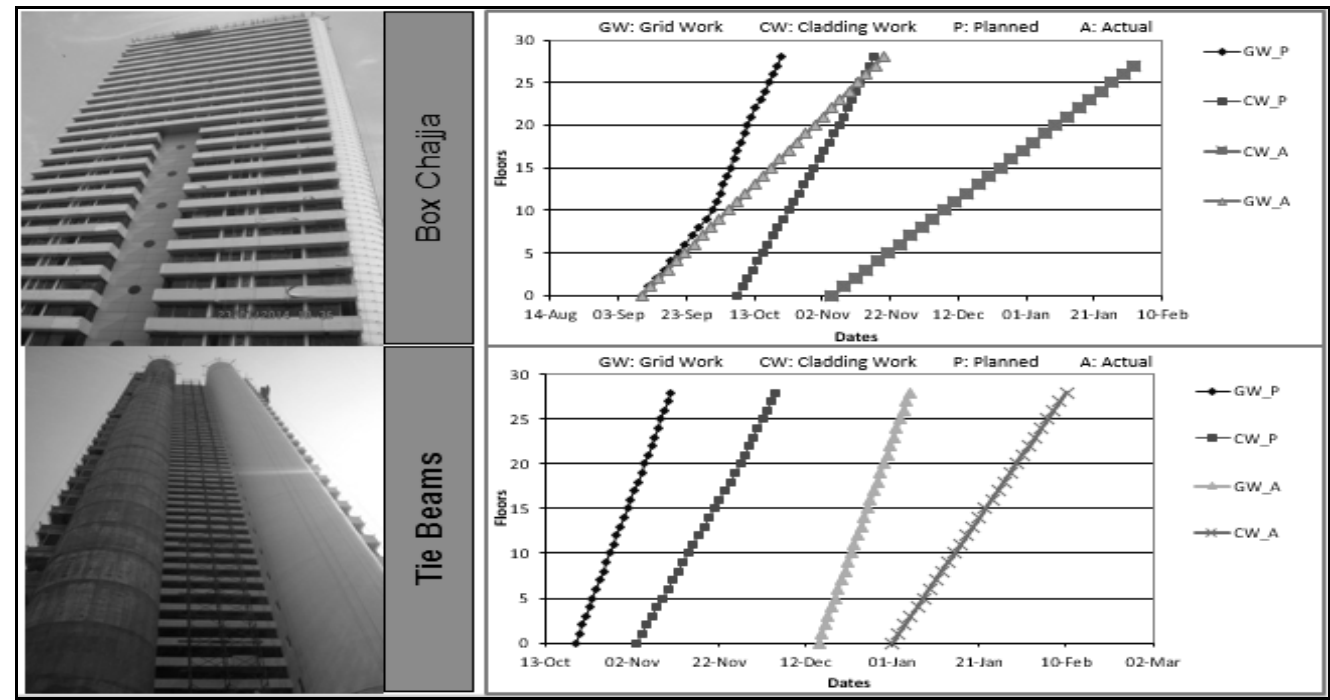

Figure 1: VSM for CSAS Cladding for Visual Tracking

Lean tools such as Last Planner System, Work Sampling, Value stream mapping, etc. were applied across various trades for effective conflict resolution and reduction of the non-value-added activities.

The following are some examples on how Lean tools were implemented on this project:

\section{VALUE STREAM MAPPING (VSM)}

Pre-Fabricated Coated Solid Aluminium Sheets (CSAS) was being used for the first time by the organisation as a Façade system for our residential building project. We were aware that this a long lead activity and was critical to timely completion of the project. Therefore, we decided to implement VSM as a Lean tool to plan, monitor and control this work package more effectively.

The organisation engaged all our concerned stakeholders including the Façade Engineering Consultant, Façade Construction Contractor, the concerned Project Engineering Team members and the Safety Engineers to help map the entire process in the Current State right from material sourcing to installation at site. This helped to design and optimize the Future State more effectively. The Non-value steps and constraints were identified and eliminated, thus reducing the turnaround time for this critical work package. 


\section{LOCATION BASED PLANNING SYSTEM (LBPS)}

Along with the earlier mentioned VSM, LBPS was also adopted for effectively completing the CSAS façade work package as per the planned schedule. Deviation in planned v/s. actual for Grid framework and subsequent cladding work which were closely monitored by LBPS. The graphical representation of activity progress of Façade work helped Project Management team to review the progress at a macro level. The mapping of actual productivity against the plan over a longer period helped in planning the subsequent Towers more effectively.

\section{WASTE MINIMIZATION}

The organization being a Green Certified Building, waste management initiatives were effectively planned for and deployed during the Design and Construction phase. This included optimization of materials through effective design, segregation of waste at source, recycling and re-use of waste generated from the project.

\section{LAST PLANNER SYSTEM (LPS)}

The organization adopted LPS with various agencies at site and motivated workmen to deliver results. The entire Project Delivery to the customer was looked upon in a holistic manner by LPS using Last Planner with Weekly Plans, Look Ahead and Constraints Analysis for collaborative planning. This helped the organisation ensure timely handover to the customers as per the committed terms of the agreement.

The entire project team along with the Top Management participated in the Lean training and Implementation Program conducted by a leading educational institute and was awarded the 1st prize at the National for one of the project (residential) for Lean Implementation in the same year.

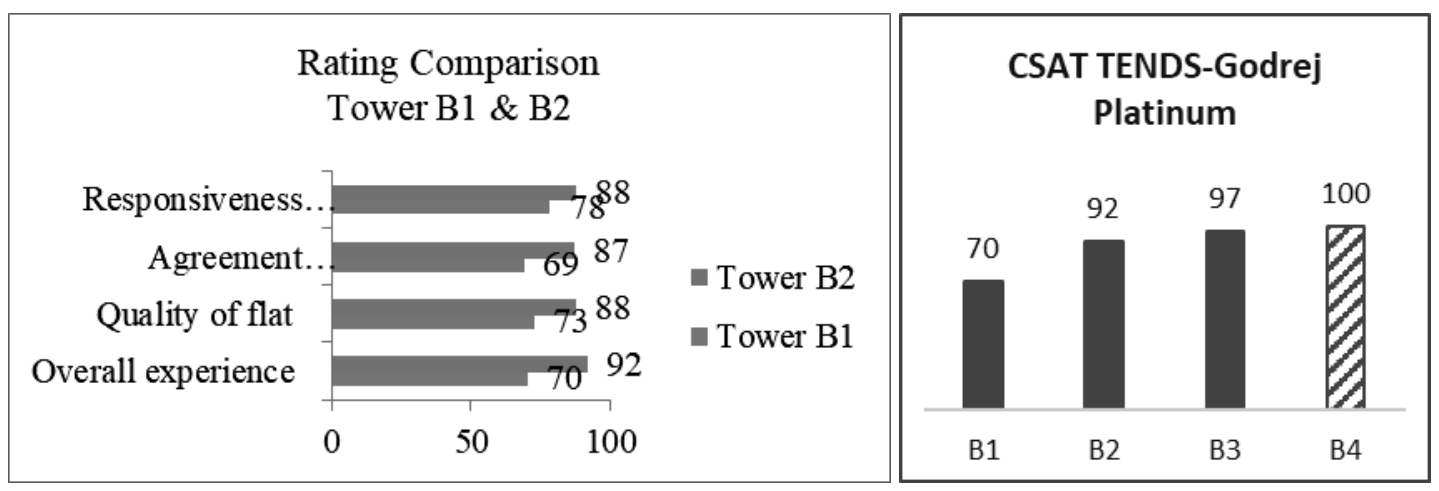

Figure 2: A Third-Party Feedback Report: Vulnerable share and Commitment share for A-type (GGE) and Tower B1 and B2

\section{RESULTS \& CUSTOMER VALIDATION}

Implementation of Lean principles should ultimately lead to benefiting the customers. As part of its ongoing journey towards Business Excellence, the organization the engaged the 
services of leading Market Research agency for conducting a detailed third-party Customer Feedback Survey. The findings clearly showed significant improvements in several key parameters. While all the improvements in customer satisfaction ratings would not have been necessarily attributed to implementation of Lean principles alone, these results helped assure us that we were on the right path on our Lean Implementation Journey.

With continued focus on meeting customer commitments, the organisation could reduce the Vulnerable Share from 9\% of the previous project to $4 \%$ over the last 7 years.

Also, the Commitment Share has improved from $83 \%$ to $87 \%$ over the same time as indicated in the adjoining graph.

KEY LEARNINGS

\section{LEAN IMPLEMENTATION AT THE ORGANIZATIONS HIGH RISE TOWERS HELPED ACHIEVE:}

Timely Project work Completion of Tower B1 \& B2

- Improved Customer Feedback (As indicated in the chart above)

- No cost overruns. In fact, through better planning and coordination the cost of construction of Tower B2 was 4\% lower than that earlier completed Tower B1.

- For LEED (Leadership in Energy and Environmental Design) certified building construction projects, the adoption of Lean principles is also helpful for waste minimization through effective waste segregation, recycling and reuse.

- Improved transparency with concerned stakeholders through team meetings for the Last Planner System.

- Improved morale of workmen, supervisors and project engineers by giving them a forum for sharing their requirements in advance and obtaining necessary support from the other team members for faster resolution of issues. Most of our project team members confirmed that adopting Lean principles helped reduce conflicts, which are often observed in fast track projects.

CASE STUDY 4 - CONSTRUCTION OF INDUSTRIAL PARK PROJECT, KHALAPUR

\section{LEAN OBJECTIVE - BROADENING OUR SCOPE FOR LEAN} IMPLEMENTATION - APPLICATION OF LEAN ON A SIGNIFICANTLY LARGER PROJECT WITH A MORE COMPREHENSIVE APPROACH, FROM DESIGN MANAGEMENT TO DELIVERY

The organization's Mega Project under the Maharashtra Industrial Policy 2013 is spread across more than 300 acres of land with an estimated built-up construction area of 3.3 million square feet.

Encouraged by the learnings, the organization decided to drive Lean to the next level from Design Management to Delivery for ensuring effective handling of multiple stakeholders' expectations. This was taken up with the strong support of Senior Management and able mentoring by a leading educational institute. At the beginning, it 
conducted a Lean Project Management Orientation workshop with various teams such as Design, Material \& Contracts Procurement, HR, Planning \& Delivery Assurance, MEP, Engineering teams for effective deployment of Lean. The biggest challenges in this project were multiple customers and the complexities in their requirements, Communication Management between multiple stakeholders, Frequent changes in design were requested by the customers.

To overcome these challenges, the organisation deployed Last Planner System which was highly useful for effective communication within the teams and it ensured decision making at right time by involving Senior Management. A project based Lean Organization structure was prepared comprising of Lean Mentor, Lean Champions, Lean Coordinator and Project Engineers.

The Concept of Big Room Meetings was introduced to Review Percentage Plan Complete (PPC), identify root causes and develop Corrective and Prevention Action (CAPA); Review Look Ahead Plans for constraint identification and their resolution, Unresolved issues which needed Senior Management intervention were taken up in another forum "Steering Committee" which comprised of Project head, Section Heads and functional Head who were actively involved in the project.

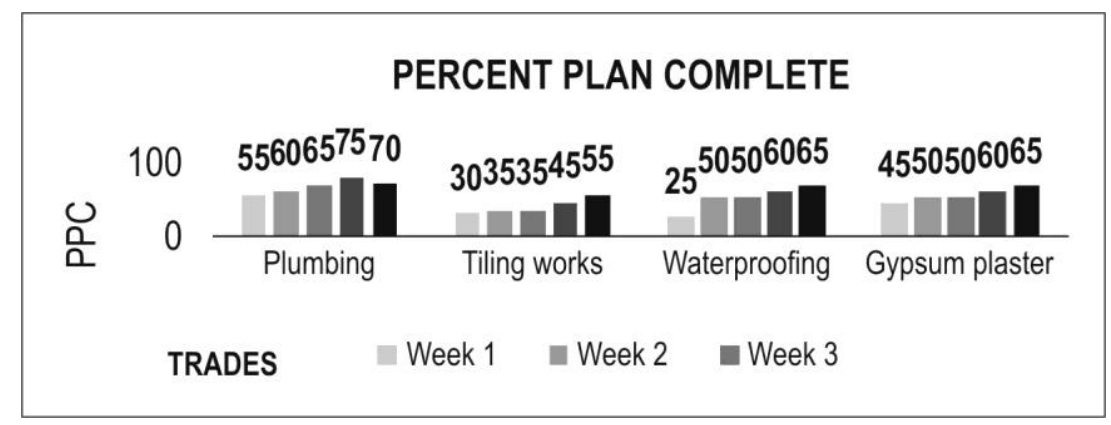

Figure 3: PPC Trends

The Steering Committee was formed to resolve issues which were put up by the teams working on the project which required senior level support and could not be resolved in Big Room meetings, resolve issues related to Contractual deviations in time and cost, To review impact on stakeholder commitments \& Timely communication from Management to the Project teams. Results show poor development and linking between the master schedule, phase schedule, look ahead plan, and commitment/weekly work plan. Performance at the commitment level and PPC become loosely linked to overall project progress. This reduces the power of the Last Planner system to forecast and increases the team's reactive approach to performing work activities especially under high uncertainty conditions. Research findings underline the deficiency in current planning systems mainly due to the lack of instructions and lack of application of standardized planning processes that clearly explain planning processes such as schedule development, feedback, responsibilities, and updates. 


\section{THE LPS CAN BE SUMMARIZED BELOW}

Hence the organization decided to amalgamate PERT and CPM with LPS and derive a balanced planning system which gave the Top Management control over key milestones related to key customer deliverables while empowering various stakeholders in planning routine activities required for successful project delivery.

5S- $5 \mathrm{~S}$ Audit Report is indicative that it is easier to implement Sort and Set in Order, however Shine, Standardise and Sustain take a lot of time since each project is unique and time bound.

It also involves recurring training to contractor and having a dedicated $5 \mathrm{~S}$ champion to drive the initiative.
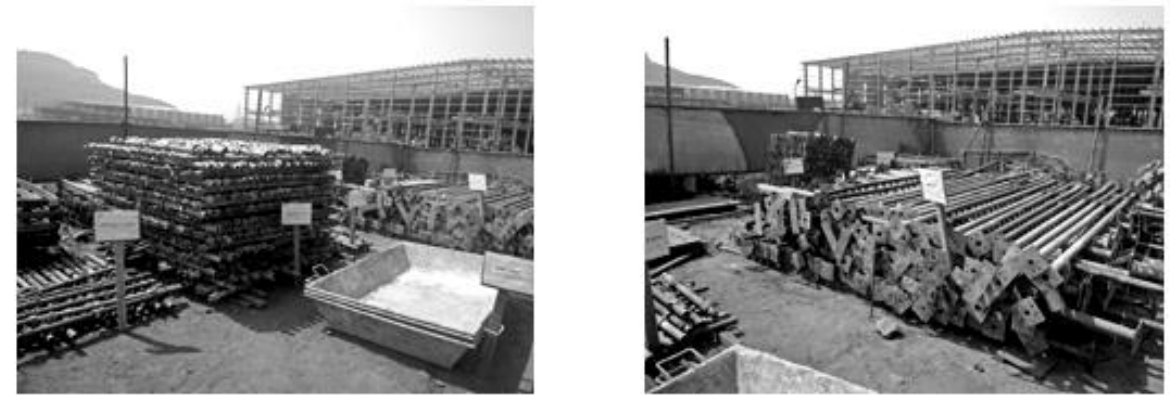

Material storage with labelling

Figure 4 - Last Planner Schedule of a Week

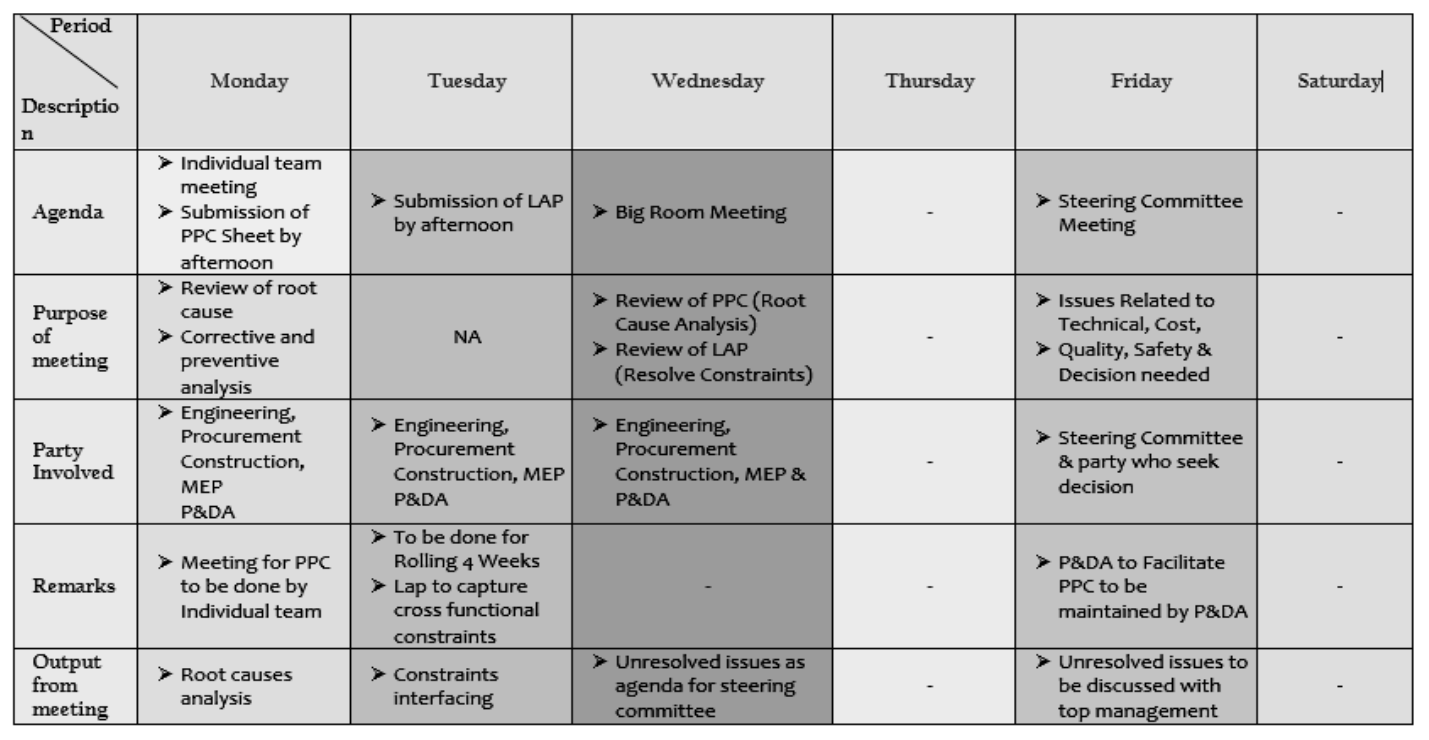

Figure 5: Photographs of a 5s stacking at Site 


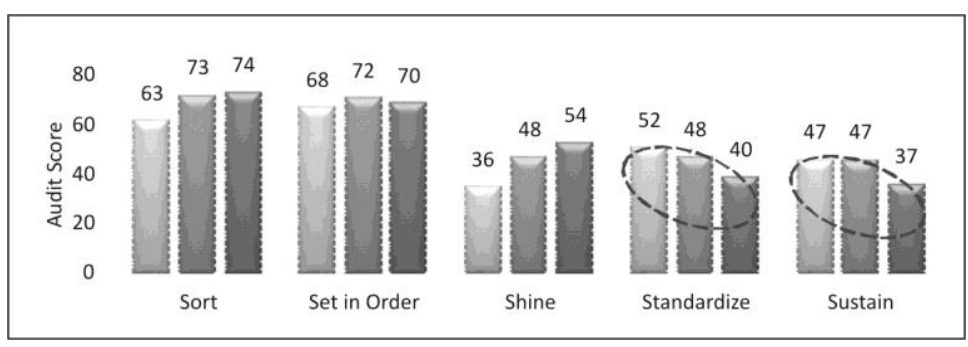

Figure 6: The 5S trends across 3 months post implementation

\section{KEY LEARNINGS}

The organization witnessed improvements in Communication and Collaboration Management by implementing LPS on the project. Almost all the stakeholders have expressed that LPS has helped them to resolve their constraints early and get the work done as per the schedule milestones. $5 \mathrm{~S}$ at site has given tremendous advantage in maintain good housekeeping standards. (refer Fig 5)

The main learning at the project is that if designers imbibe the Lean philosophy, larger benefits can be reaped such as lesser design iterations which will not only help the Project execution team to complete their deliverables but also helps Procurement and Contracts team to complete the Tendering and Contract award process faster.

\section{SOME OTHER INITIATIVES: - VENDORS MEET}

The organization's Contracts \& Procurement Team conducted a Vendors' Meet to realign them to our Vision, Mission and Values (VMV) and provide an enabling environment for becoming credible partners. Vendor Feedback was also sought to identify focus areas for improvement and initiatives to address these were taken up. (refer fig 7)

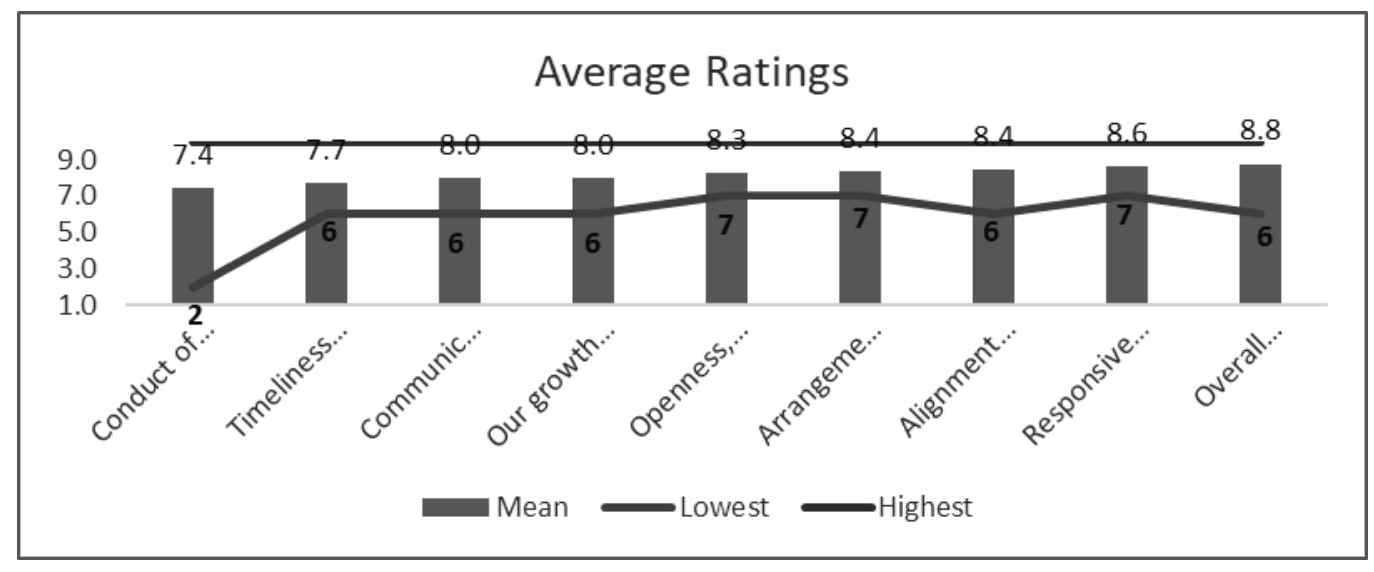

Figure 7: Vendor Feedback Ratings indicating good performance 


\section{CONCLUSION}

The implementation of Lean Construction has helped in successful execution and commissioning of our projects by:

\section{PARTNERING}

- Creation of better relationships with our stakeholders (Case study 1 \& 2)

- Identification of constraints and non-value adding activities (Case study 3 )

- Trust \& Transparency (Case study 3 \& 4)

- Open communication (Case study 1, 2, 3 \& 4)

\section{RESOURCE OPTIMIZATION}

- Waste minimization \& 5S implementation (Case study 3 \& 4)

- Smooth process flow for efficient project delivery (Case study 4)

- Better monitoring and controlling using "pull” mechanism (Case study 3 \& 4)

- Early flag off to arrest the potential delays (Case study 3 \& 4)

- Enhanced safety using technology (Case study 4)

\section{BARRIERS IN THE ORGANIZATIONS LEAN JOURNEY}

Lean is perceived as an additional exercise to existing work assignments, tendency of project team members to focus on Lean tools rather than effective deploying Lean philosophy. Lean Tools are only enablers in effective implementation of the Lean philosophy, Project teams expect the benefits of Lean to be seen immediately.

Moreover, the success of Lean Construction is not very evident and easy to quantify into measurable units. Also, since most organisations have improvement initiatives running parallel to Lean implementation, the benefits of Lean may not be attributed with certainty to Lean alone.

\section{ROAD MAP FOR FUTURE STRENGTHENING OF LEAN CULTURE:}

Lean is not something complex it can be summarized as a philosophy to drive continuous improvement with customer focus by doing three things right - eliminating waste, simplifying everything and creating a flow. In the future, the organisation plans to further strengthen the Lean Culture in our business operations through the following initiatives:

1) Implementing Lean in Conceptual Design stage of the project

2) Quarterly Lean Newsletters.

3) Improving the Productivity of Operations at Construction sites by Lean Principles

4) Reduction of Customer Complaints by $33 \%$

5) Improving Efficiency at all Sites.

6) Creating a Lean Culture in the organization through Human Resources Trainings. 


\section{REFERENCES}

Ballard, G., and Howell, G. (1997) - "Implementing Lean Construction: Improving downstream performance" Lean Construction, Balkema, Rotterdam, Netherlands

B Singh, SK Sharma - (2009) - Measuring Business Excellence.

Bhim Singh- (2010) - Lean implementation and its benefits to production industry.

Farook R. Hamzeh, Glenn Ballard and Iris D. Tommelein (2015) - Improving Construction Work Flow -The Connective role of Look Ahead Planning.

Jagdish R. Jadhav, Shankar S. Mantha, Santosh B. Rane, (2014) "Exploring barriers in lean implementation", International Journal of Lean Six Sigma, Vol. 5 ‘

Max Allway, Stephen Corbett (2002)-Shifting to lean service: Stealing a page from manufacturers' playbooks

Niranjan Mudholkar (2016) - "There is always a better way of doing things" The Machinist

Raghavan, N., and Satyanarayana, K.N. (2011). "Lean Construction - An introduction to Concepts, Principles and Practices". The Masterbuilder, Oct. 2011

Saja Albliwi, Jiju Antony, Sarina Abdul Halim Lim, Ton van der Wiele, (2014) "Critical failure factors of Lean Six Sigma: a systematic literature review", International Journal of Quality \& Reliability Management. 